\title{
Analysis of Power Categories Problems in National Undergraduate Electronic Design Contest
}

\author{
Wenna Dong \\ School of electrical and electronic engineering, North China Electric Power University, BeiJing \\ 102206, China \\ 836378629@qq.com
}

Keywords: NUEDC, Power Categories Problems, Switching Power Supply.

\begin{abstract}
This article describes the power categories problems that often appear in National Undergraduate Electronic Design Contest, and gives a switching power supply design and power performance test results. Finally, the article summarizes the knowledge of power categories problems involved as well as the contents participants to master.
\end{abstract}

\section{Introduction}

National Undergraduate Electronic Design Contest was one of the students academic competitions promoted by the Ministry of Education, a college-oriented mass scientific and technological activities, aimed at promoting higher education for information and electronics disciplines the reform of curriculum system and content. The race is associated with the university professional curriculum system and curriculum reforms closely, to promote the development of the teaching and laboratory building. The theme of this competition can be classified into seven categories: control category, power category, high frequency radio category, amplifiers category, instruments and meters category, data acquisition and processing category, signal source category ${ }^{[1]}$. Among them, the power problem appears in almost every session, and there have been items: simple numerical control direct current power supply, DC power supply, digital controlled DC current source, three phase sine wave inverter power supply, switching power supply, gridconnected PV simulation device, power collection of chargers and switching power supply paralleling power supply system ${ }^{[2]}$.

\section{Analysis and Design of Switching Power Supply ${ }^{[3][4]}$}

This problem requires to design a switching power supply. Due to the high efficiency, small volume, light weight, switching power supply is currently under rapid development. It uses the power semiconductor devices as switches, by adjusting the duty cycle of the switch to adjust the output voltage. 


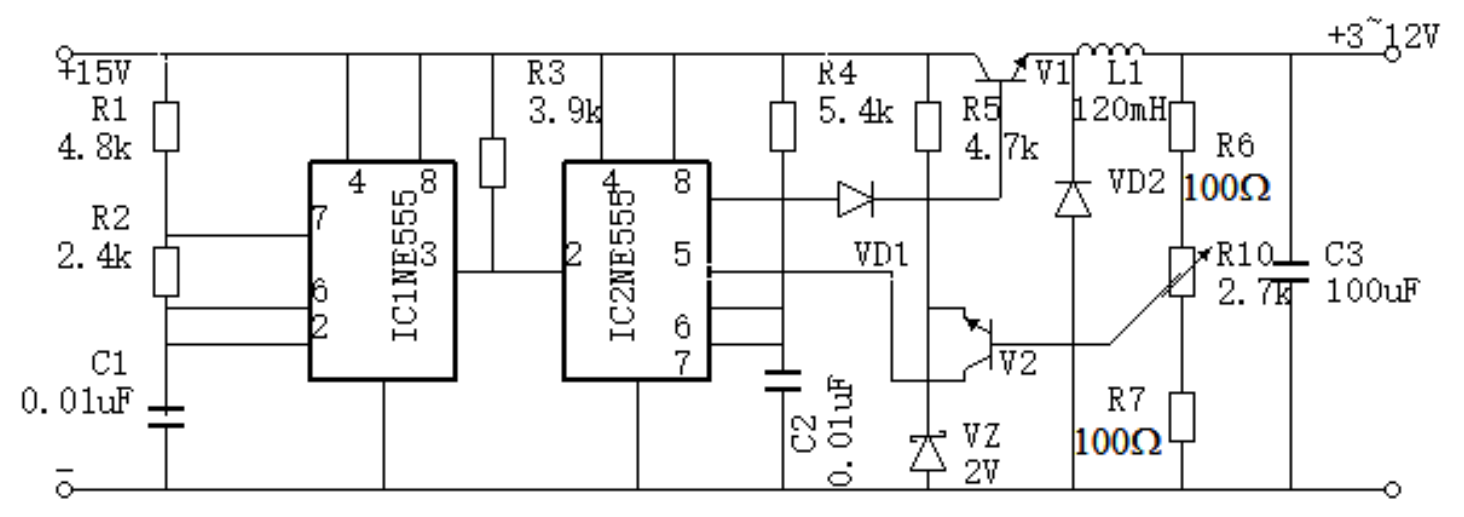

Figure $13 \sim 12 \mathrm{~V}$ switching voltage adjustable regulated power supply circuit

\subsection{Circuit Principle}

R1, R2, C1 and 555 time base circuit IC1 compose non-steady-state harmonic oscillator. And oscillation frequency is determined by the value of R1, R2, C1. The load of resistor R3 is IC1, and IC1 outputs pulse signal.

R4, C2 and IC2 make up monostable multivibrator, and the pulse signals outputted by IC1 are directly sent to the 2 nd leg of IC2. When the trigger level is high electricity, monostable trigger is in steady state, outputs low level, and adjusts the switch V1 in off state. The diode VD1 is to ensure that V1 is in the state of cut-off as the trigger outputs low levels. When low level arrives, the monostable trigger flips, outputs high level, and then V1 saturates and conducts At the same time, the power charges the capacitance $\mathrm{C} 2$ through $\mathrm{R} 4$. When the potential on the $\mathrm{C} 2$ is higher than the IC2 5 feet's, monostable trigger outputs the low level, backs in steady state again. V1 cuts off, and capacitance C2 discharge soon through the IC2 's discharge tube. And the cycle repeats which makes the V1 work in switch state. In the figure L is energy storage inductors, and VD2 is the flow diode.

\subsection{The Process of The Whole Circuit's Automatic Voltage Regulator}

After sampling circuit's detection, output voltage is compared with reference voltage, which can detect the error signal. Error signal amplified with error amplifier circuit can automatically adjust the IC2 5th foot 's potential level and change the pulse width of trigger output signal .

Adjust switch tube V1 break-over time, so as to achieve the purpose of automatic voltage regulator. The size of the output voltage is adjusted by potentiometer RP.

\section{Test Results of Power Performance}

Table 1 Test results of power performance.

\begin{tabular}{|c|c|}
\hline Test Contents & Test Results \\
\hline Output Voltage Range & $3 \sim 12 \mathrm{~V}$ \\
\hline Output Overload Protection & $110-150 \%$ \\
\hline Output Overvoltage Protection & $115-150 \%$ \\
\hline Withstand Voltage Test & $1.5 \mathrm{KV} \mathrm{AC} / 1 \mathrm{~min}$ \\
\hline Opening Time & $50 \mathrm{~ms}$ \\
\hline
\end{tabular}




\section{The Knowledge Needed to Acquire}

- The working principle, structure and circuit of variable frequency power supply and PWM switching power supply

- Design and fabrication of AC power transformer

- Design and manufacture of high frequency switch power supply transformer

- Design and production of AC rectifier and filter circuit

- Design and fabrication of chopper and drive circuit

- Design and manufacture of the inverter and driver circuit

- Design and fabrication of current and voltage detection circuit

- Design and making of overcurrent and overvoltage protection circuit

- Design and making of effective value detection circuit

- Design and making of ADC and DAC circuit

- Design and making of DC-DC boost type switch power circuit

- Design and making of DC-DC buck type switch power circuit

- Design and making of DC regulator circuit

- Design and making of single tablets machine, and FPGA, and ARM minimum system circuit

- Design and making of micro-controller peripheral circuit (display, and keyboard, and switch)

\section{Conclusions}

Power categories problems usually involve knowledge of power electronics technology, and basic knowledge is primarily analog electronic circuits, especially MOS pipe applications. It may also involve the amplifier, amplifier, and so on. In addition, students also need to be able to use $\mathrm{SCM}$, and related content will involve single-chip system, AD/DA conversion, digital/LCD display, keyboard input and so on ${ }^{[3]}$.

The most difficult part of power supply problems are to design a power circuit and access to indexes, such as output voltage, output current, as well as the necessary precision index. There are also some parameters of power, such as the load-carrying capacity, ripple, etc.

\section{References}

[1] Xingming Yang. National undergraduate electronic design contest problem analysis and enlightenment [j]. Electrical and electronic teaching journal, 2007, (04): 54-56.

[2] Lihua Wang. Undergraduate electronic design competition in power supply problem analysis [j]. Science and technology, 2013, (01): 152-154

[3] Yufei Song, Shen Weikang. Small adjustable switching power supply design [j]. Information technology, 2011, (07): 44-47+52.

[4] Xianwei Qi. Design and construction of multiple-output of switching power supply [d]. Dalian University of technology, 2015.

[5] Official website of the National Undergraduate Electronic Design Contest.http://www.nuedc.com.cn/. 